\title{
"SEXUIDAD", TRÁNSITOS Y DEVENIRES DE LA EXPERIENCIA CORPORAL EN TORNO A LA SEXUALIDAD. APORTES PRÁXICOS DESDE LA EDUCACIÓN FÍSICA EN TIEMPOS DE INCERTIDUMBRE
}

\author{
"SEXUITY", TRANSITS AND BECOMING OF CORPORAL EXPERIENCE \\ AROUND SEXUALITY. PRAXICAL CONTRIBUTIONS FROM PHYSICAL \\ EDUCATION AT TIMES OF UNCERTAINTY
}

"SEXUIDADE", TRÂNSITOS E MUDANÇAS DA EXPERIÊNCIA
CORPORAL EM RELAÇÃO À SEXUALIDADE. APORTES PRÁXICOS
DESDE A EDUCAÇÃO FÍSICA EM TEMPOS DE INCERTEZA

Cristian Camilo Castillo Monroy ${ }^{1}$

\section{Resumen}

\begin{abstract}
El siguiente artículo de reflexión ofrece un aporte pedagógico a las prácticas discursivas contemporáneas de la educación física, a partir de una reflexión en torno a la sexualidad, o "sexuidad", como posibilidad estética que puede devenir en experiencias transformadoras de la realidad. Se tiene en cuenta el pensamiento de autores como Gillez Deleuze, Michel Foucault y Hanna Arendt para pensar en otras formas de ser y vivir cuerpo en comunidad, apelando a la sexuidad, como un neologismo que pretende superar los reduccionismos y el desprecio que las ciencias modernas ejercen sobre el cuerpo y la vida. Las mismas ciencias en las que se sustentan las prácticas de la educación física, a partir de algunas de sus "tendencias" instaladas como régimen de pensamiento. Superar estas prácticas y estos discursos es contemplar una posibilidad de develar los pequeños fascismos que se instalan cotidianamente en las relaciones que ejercen unos cuerpos con otros y en las cuales el dispositivo de la sexualidad es el campo de batalla. Preguntarse hoy por la vida, fundamentalmente por la vida del otro es preguntarse por su cuerpo, esto implica darle un nuevo valor al mismo, además de escudriñar y cuestionar algunos discursos a la hora de referirse a la sexualidad, sus reduccionismos prácticos y sus respectivos usos a la hora de educar físicamente. Aquí cabe pensar en una nueva y consistente praxis, que incluya la pluralidad de voces y subjetividades, en un proyecto erótico en el cual los cuerpos transiten y la "experiencia corporal" pueda ser pensada de otro modo.
\end{abstract}

Palabras clave: experiencia corporal; sexualidad; dispositivo; sexuidad; cuerpo sin órganos

\section{Abstract}

The following article intends to give a pedagogical contribution to the contemporary discursive practices of physical education, from a reflection on sexuality, or "sexuity", as an aesthetic possibility, which becomes in other transformative experiences of reality. In this sense, the thinking of authors such as Gillez Deleuze, Michael Foucault and Hanna Arendt is taken into account to think about other ways of being and living body in community, appealing to "sexuity", as a neologism that aims to overcome the reductionisms and contempt that modern sciences exert on the body and life; the same sciences of which Physical Education sustains its practices, from some of its tendencies that are installed as a regime of thought. To overcome these practices and these discourses is to contemplate a possibility of transforming the small fascisms that are installed in everyday life from the relationships of some bodies with others, where the role of the device is crucial. To ask

1 Licenciado en Educación Física, Universidad Pedagógica Nacional. Correo electrónico: fef_ccastillom046@pedagogica.edu.co. Orcid: 0000-0003-1125-7322. 
oneself today for life, fundamentally for the life of the other is to ask about your body, this involves scrutinizing and questioning certain discourses and devices, in this case sexuality, its practical reductionisms and their respective uses when it comes to educating physically, here it fits make a reflection and a contribution to Physical Education, from the problem discussion of their practices, to think of a new and consistent practice.

Key words: Body experience; sexuality; device; sexuity; body without organs

\section{Resumo}

O seguinte artigo tem a pretensão de oferecer uma contribuição pedagógica às práticas discursivas contemporâneas da educação física, partindo duma reflexão em relação à sexualidade o "sexuidade", como possibilidade estética que muda em experiências outras transformadoras da realidade. Neste sentido tem-se em conta o pensamento de autores como Gillez Deleuze, Michael Foucault e Hanna Arendt para pensar em outras formas de ser e viver corpo em comunidade, apelando à "sexuidade", como neologismo que pretende superar os reducionismos e o desaprecio que as ciências modernas exercem sob o corpo e a vida; as mesmas ciências nas que se sustentam as práticas da Educação Física, partindo de algumas de suas "tendências" instaladas como regime de pensamento. Superar essas práticas e estes discursos é contemplar uma possibilidade de transformar os pequenos fascismos que instalam-se na cotidianidade começando das relações de uns corpos com outros, nas quais o papel do dispositivo é fundamental. Questionar-se hoje pela vida, fundamentalmente pela vida do outro é interrogar por seu corpo, isso envolve inquirir e questionar alguns discursos e dispositivos, neste caso a sexualidade, seus reducionismos práticos e seus respectivos usos à hora de educar fisicamente. Aqui cabe fazer uma reflexão e um aporte à Educação Física, começando desde a problematização das suas práticas, para pensar numa nova e consciente praxis.

Palavras-chave: Experiência corporal; sexualidade; dispositivo; sexuidade; corpo sem órgãos

Para citar este artículo:

Castillo Monroy, C. C. (2019). “Sexuidad”, tránsitos y devenires de la experiencia corporal en torno a la sexualidad. Aportes práxicos desde la educación física en tiempos de incertidumbre. Lúdica Pedagógica, 30, 59-70. https://doi.org/10.17227/ludica.num30-11105 


\section{INTRODUCCIÓN}

Este artículo ofrece un aporte pedagógico al Proyecto Curricular de Licenciatura en Educación Física (PCLEF), apuesta curricular de la Universidad Pedagógica Nacional que lleva casi dos décadas en Colombia, con el fin de señalar algunas consideraciones respecto al potencial de la experiencia corporal, objeto de estudio de este programa, identificando las prácticas discursivas en las que se disputa esta disciplina, las cuales remiten a lo que algunos teóricos han planteado como tendencias o corrientes de la educación física y, consustancialmente, ver su configuración como régimen de pensamiento.

Ello devela las herramientas pedagógicas, discursivas ${ }^{2}$ y prácticas con las que cuenta el maestro para interpretar, y luego transformar éticamente, la realidad presente, gracias al saber que se construye dialógicamente. Es decir, el ejercicio práxico ${ }^{3}$ que la educación física debe asumir para transformar-se realmente en eso llamado pedagogía.

Tomando como horizonte discursivo la experiencia corporal, se pretende problematizar los límites de la misma con la sexualidad, dimensión humana, como elemento desequilibrante y provocador, el cual cuenta con escasas reflexiones en este campo disciplinar, pero representa una fuerte herramienta de resistencia a los ejercicios homogenizantes e individualizantes en los que, incluso, puede caer esta disciplina cuando asume la experiencia corporal como objeto de estudio.

Asumir este "objeto de estudio" es producto de reflexiones práxicas que advienen al giro corporal y con ello a un paradigma incluyente de las dimensiones como la motricidad y la corporeidad. Sin embargo, esto es preciso problematizarlo, en cuanto ejercicio pedagógico de transformación permanente y respon-

2 Por discurso se entenderá el campo de regularidad para diversas posiciones de subjetividad, es un conjunto en el cual puede determinarse la dispersión del sujeto y su discontinuidad consigo mismo (Foucault, 1970, p. 90).

3 Por praxis humana se entenderán los dos aspectos fundamentales señalados por Alfonso Sánchez Vásquez (2003), el primero como intención individual que persigue un fin determinado, el segundo como intención cuya actividad individual se integra con otras praxis en el nivel social produciendo unos resultados que desbordan su conciencia y su voluntad y pasan a un plano global (p. 17), en otras palabras y en términos de responsabilidad pedagógica, se trata de transformación en contexto. sabilidad ética y política, pues es muy posible que las resistencias sean funcionales o, en otras palabras, sean las que los dispositivos necesitan para perpetuar un régimen de pensamiento alienante y adecuado a un mundo neoliberal, urgido en "mundializar" las prácticas corporales, los deseos y con ello las experiencias, una de ellas, la sexualidad, para la producción de subjetividades de cierto tipo de cuerpos.

Cabe mencionar que la caja de herramientas en la cual se apoya este artículo en su pretendido ejercicio práxico, toma elementos fundamentales de Michel Foucault (1979), en su análisis arqueológico del discurso, a partir de las concesiones, estrategias, los juegos de reglas de formación, lo dicho y lo no dicho, la problematización de lo enunciado por encima de lo no enunciado, el porqué de la exclusión de lo no dicho y la difusión de un saber con la finalidad de identificar las relaciones entre saberes del cuerpo y poder, fundamentalmente con el nacimiento de la psyche.

Es necesario mencionar que este ejercicio hermenéutico parte de "poner en paréntesis" a la experiencia corporal, para lo cual se establecieron tres categorías de análisis tejidas, que permiten sustentar la ruptura que se pretende generar con la sexualidad en búsqueda de nuevas enunciaciones y lenguajes ampliando el espectro discursivo de la experiencia corporal y, con ello, contribuir con herramientas pedagógicas a la praxis educativa, fundamentada en la corporeidad, la motricidad y la sexualidad como una posibilidad emancipatoria, susceptible de ser educada y que devenga en otras experiencias capaces de tejer comunidad y nuevos juicios estéticos en momentos inciertos por los cuales pasa el país luego de un "posacuerdo".

En este orden de ideas, las categorías entretejidas por desarrollar a lo largo de este artículo son la corporalidad, a partir de los valores dados al cuerpo en un momento determinado; los discursos dentro de la educación física que sustentan dichos valores, teniendo en cuenta algunas de sus tendencias (Mosquera et al., 2005), y, por último, la subjetividad desde los dispositivos y ejercicios de agenciamiento, como el consumo de identidades, pero también otras narrativas no visibilizadas y con ello otras prácticas corporales posibles que devienen en experiencias sensibles e incluidas dentro de la educación física. 


\section{ALGUNOS PROLEGÓMENOS DISCURSIVOS DE LA EDUCACIÓN FÍSICA, EL NACIMIENTO DE LA PSYCHE}

Bastos son ya los recorridos epistémicos e históricos que se le han dedicado a la educación física y más aún cuando estos pretenden referirse a su tradición moderna y dual. Partiendo de lo anterior, la idea por desarrollar es la incidencia epistémica en la práctica pedagógica del licenciado en Educación Física actualmente en Colombia, para lo cual se toman como referentes discursivos a la condición física y al deporte — considerados actualmente tendencias de la educación física- este última, propio de esta disciplina, en cuanto emerge dentro de la escuela.

Es preciso tratar de escudriñar, entonces, los valores dados al cuerpo y con ello a la experiencia y la condición humana latinoamericana, particularmente, la colombiana. De ahí que sea necesario volver a las raíces de la filosofía occidental, pues fueron la influencia griega y la moderna, dualista y dicotómica, aquellas que conquistan esta región, y de las cuales se hereda, como narrativa hegemónica, todas las ciencias auxiliares de la educación física a partir de las cuales ha sido posible pensar al cuerpo como antítesis del alma $\mathrm{y}$ al que solo es posible intervenirlo, estudiarlo y educarlo como soma.

Comprender esto no es posible sin regresar a la Grecia homérica presocrática y su crisis cultural (Havelock, 1994), luego del nacimiento de un nuevo pensamiento que revolucionaría la comprensión del hombre en relación consigo mismo (experiencia), con el conocimiento y por defecto con la educación, además de la relación con la materia (naturaleza) y la cultura. Sócrates y Platón, pioneros en enunciar la palabra psyche, pretendieron superar una tradición oral, poética en la que el hombre homérico, dócil y sin consciencia de su existencia, no se preguntaba y reproducía lo que oía, veía y recordaba, pero que era a partir de lo cual, se construían y compartían ciertos sentidos, luego se hacía comunidad.

En esta empresa, Platón se propone dos tareas fundamentales para romper con la experiencia poética. La primera, la afirmación de un sujeto, una personalidad autónoma y responsable; y la segunda, el establecimiento de un objeto, es decir, un área del conocimiento que ha de ser enteramente abstracta
(Havelock, 1994). En esta última, lo que Platón defendía, en resumidas cuentas, era la invención de un lenguaje abstracto, un ejercicio científico descriptivo, para reemplazar el lenguaje propio de la memoria oral, dentro de la cual identificó 3 categorías propias del pensamiento griego homérico por superar: la doxa, relacionada con la opinión pública e irreflexiva; la mimesis o reproducción de la cultura y, por último, la sintaxis narrativa, relacionada con la poesía o el myths que representa la antítesis e incluso el enemigo del logos y por lo tanto del ser.

De entrada, y en este breve recorrido, es posible identificar la manera como se instalan ciertos dispositivos en un momento dado y en unos juegos de verdad cuya importancia radica en develar, precisamente qué es lo verdadero. Una de las tareas de este artículo es cuestionar cómo el concepto de la psyche, que inicia el pensamiento moderno y dual, toma fuerza en la filosofía moderna y cristiana con Santo Tomás y otros pensadores (algo que se desarrollará en líneas posteriores) quienes estimulan un solipsismo capaz de romper las relaciones del cuerpo con el mundo y con los demás cuerpos, es decir, niega la posibilidad de interpretar y comprender el cuerpo en sus relaciones, un reclamo de Spinoza ${ }^{4}$ en su ética (1980) al que hasta hoy, no se le ha hecho justicia.

Por lo tanto, es imperativo pensar en quiénes, supuestamente, son los que tienen psyche, luego, cuáles son los discursos que avalan tales enunciaciones y, por supuesto, cómo ese dispositivo incide en la percepción, relación e incluso negación del otro distinto desde su cuerpo o su corporalidad; es decir, cómo se han justificado, perversamente, desde el dispositivo del alma y el desprecio por ciertos cuerpos, el racismo, clasismo, machismo, regionalismo, la xenofobia, las banderas políticas a muerte y demás, en un país como Colombia que encarna, per se, una estética de lo atroz (Barrero, 2011).

4 Para Spinoza, alma y cuerpo son una sola, nuestras acciones y pasiones corresponden a la naturaleza de que precisamente somos seres corpóreos, ahora bien, existen relaciones en las cuales el cuerpo humano aumenta o disminuye su capacidad de obrar, a partir de esas afecciones en las que se implican las leyes de la naturaleza de movimiento o reposo, Spinoza afirma que nadie sabe lo que puede un cuerpo en virtud de su naturaleza y nadie puede saber lo que no puede salvo que el alma lo determine. Nadie pues, según él, conoce la fábrica del cuerpo para entender todas sus funciones, solo es posible saberlo en las afecciones (afectto) que le acontecen. (Spinoza, 1980, pp. 124-128). 
Para justificar lo anteriormente enunciado, es clave exaltar la importancia que, a partir de Platón, se le da al alma como enunciación del yo. Sin embargo, se reconoce una minoría cultivada, la cual, con la psyche, alude como un espíritu pensante capaz de deliberar en el plano moral y también de alcanzar el conocimiento científico; su antítesis, el cuerpo o cadáver, aparente morada del ego (Havelock, 1994).

Esta forma verdadera y eterna, para Platón y Aristóteles (Arendt, 2005), de vivir y ser cuerpo que se instala como forma de gobierno, sin duda también afecta las relaciones con otros cuerpos, en la medida que los seres humanos se "resistan no solo a las tentaciones del poder, la riqueza y los placeres, sino también las de la poesía” (Havelock, 1994, p. 195); incluso, antes que Platón, Heráclito decía: “Los demás, los satisfechos con los placeres que les proporciona la naturaleza, viven y mueren como animales" (Arendt, 2005, p. 31). De esta forma, es posible apreciar el desprecio por el cuerpo desde Platón; sin embargo, un desprecio que arroja ciertos valores respecto al movimiento, al cuerpo, a la verdad y a la vida en cuanto tal, asuntos de interés para este texto.

Pero también Aristóteles hablaba de la quietud y la contemplación que permitiría vislumbrar

cualquier movimiento del cuerpo y del alma, así como del discurso y del razonamiento, han de cesar ante la verdad. Esta tratase de la antigua verdad del ser o de la cristiana de Dios vivo, únicamente puede revelarse en quietud humana (Arendt, 2005, p. 28).

Estos valores dados al cuerpo, a costa de su propio desprecio junto con la vida, además de la exaltación del alma, como lo verdadero, arrojan indicios de uno de los orígenes discursivos de la educación física que ubican al movimiento en un lugar eminentemente rudimentario y despersonalizado, carente de cualquier voluntad, ética y relación con el otro, con la cultura, mucho más en lo referente a la técnica. Platón hace una clasificación tripartita del hombre, como aficionados a la técnica, a los espectáculos o como hombres de acción, lo cual, en Sócrates, antes que Platón, se reflejaría en una descalificación hacia los políticos, los poetas y los artesanos (Havelock, 1994).

Con Aristóteles, continuaría un desprecio por el cuerpo, exponiendo su posición frente al movimiento, que Arendt (2005) enuncia como vita activa o con- templación, concepto de suma importancia en su trabajo, que, en gran medida, devela parte de la condición humana, en relación, fundamentalmente, con su propia vida. Tanto, que en una dimensión como el trabajo, alude esta autora, para Aristóteles "ningún trabajo del hombre puede igualar en belleza y verdad al cosmos físico, que gira inmutablemente y eternamente sin ninguna interferencia del exterior, del hombre o de Dios" (p. 28). El lugar de Dios como verdad y figura fundamental de toda acción humana, no resiste análisis, determina la experiencia humana, en tanto interviene en el sujeto un ejercicio de gobierno, en la búsqueda de una vida eterna, no desde la praxis, sino desde la contemplación tehorica la cual aleja de toda relación real del ser humano, esto es, del cuerpo con el mundo y con los otros cuerpos que lo exceden y se enuncian como otros e impide percibir, sentir y vivir el cuerpo en el complejo entramado de relaciones que le dan sentido a su existencia.

Esta filosofía, heredera del pensamiento occidental hasta hoy, afirma en su trabajo que el concepto de vita activa, cambia sus enunciaciones luego de la caída del Imperio romano, debido a que predicaba una vida individual imperecedera, lo cual garantizaba y cambiaba sustancialmente la relación con la propia vida en términos de buscar la inmortalidad, pues es propia y esencial de la humanidad para ese momento. Por su parte, Santo Tomás enuncia la vita activa como una forma de gobierno en la que se busca la tranquilidad del alma, aquietando las pasiones que facilitan la contemplación y necesidades del cuerpo humano que tiene en común con los animales (Arendt, 2005). Sin duda, esta mirada respecto a la vida en búsqueda de la inmortalidad propia a partir de la exaltación de la psyche, impide apreciar el cuerpo como inmanencia y, en consecuencia, su finitud, luego la importancia de la presencia de los demás cuerpos y la posibilidad de tejer lasos sensibles, afectuosos y desinteresados.

Hasta ahora, y en este breve epítome, la experiencia humana ha sido corporal, en detrimento y subvaloración precisamente del cuerpo y de la vida como experiencia sensible y expansiva que culmina con la muerte. Esto, como se ha visto, ha sido posible a través de un discurso instalado como verdad y como dispositivo en el cual "el predominio de los sentimientos de desplacer sobre los de placer es la causa de aquella moral y aquella religión ficticias; pero ese 
predominio suministra la fórmula de la decadencia" (Nietzsche, 2001, p. 15), esto es, en términos de educación física y particularmente de la escolarizada, lo que lleva a preguntarse respecto a qué tipo de experiencias ha propiciado y propicia en el ser humano una disciplina eminentemente práctica en la que hay una intervención directa de y en los cuerpos.

Es bajo la necesidad de esa verdad que el ser humano se propone como horizonte y proyecto, esto es, como experiencia. Cabe enunciar que esas verdades se instalan en las formas de ser-en-el-mundo. Foucault (1977), en su empresa por un estudio genealógico de la moral, prestando atención al final de su vida a la sexualidad, enuncia cómo, a través de este dispositivo, ${ }^{5}$ ha sido posible normalizar al sujeto, esto es, grosso modo, poner a circular un discurso en los seres humanos capaz de proliferarse e instalarse en la red de formas de vivir de los sujetos, sin que ellos lo perciban, pero produciendo cierto tipo de cuerpos y subjetividades.

Para ello, es necesaria la emergencia de prácticas discursivas que, en permanente dinámica, estén ejerciendo la idea de libertad. En otras palabras, el sujeto es, supuestamente, libre de vivir su sexualidad; sin embargo, hay también discursos que avalan lo que debe hablarse o no respecto a la sexualidad, siempre desprovistos de reflexiones éticas, estéticas, ontológicas y existenciales, pero con una carga fuertemente moral y patológica amparada en reduccionismos cientificistas desde la scientias sexualis (Foucault, 1977).

En las líneas siguientes, se tratará de llevar a cabo una reflexión en torno a la sexualidad que permita repensarla como elemento de sustancial importancia reflexiva, en la praxis de la educación física hoy, especialmente cuando Colombia transita en tiempos de incertidumbre y la experiencia corporal merece ser pensada desde su potencia, desde lo que puede. El escenario, convoca a maestras y maestros a superar las verdades que se han pretendido instalar hegemónicamente como trascendentes y en su lugar volver a las cosas mismas, a prestarle atención a la singularidad y diversidad de los cuerpos, a lo que narran, a sus pasiones, deseos y a lo que pueden en su relación

5 Se entenderá por dispositivo, en términos foucaultianos, una red de relaciones en las cuales se imbrican el saber y el poder y en las que se hallan instituciones y prácticas discursivas. con otros. La sexualidad allí, obtiene un papel importante cuando se deja de ver como un asunto del soma que puede pervertir la psyche, en cuanto esta última se ocupa de gobernar la genitalidad, los órganos y la lógica reproductiva subyacente en el dualismo hombre-mujer. Para en su lugar ver la sexualidad como pura apertura y realidad total del ser que no tiene, sino que es cuerpo y a partir de la cual es necesario educar pues en ella se manifiesta la menesterosidad y dadivosidad de los cuerpos (Suarez, 1995, p.81) esto es, su finitud.

\section{DE HACERSE A UN "CUERPO SIN ÓRGANOS", HACIA UN PROYECTO ERÓTICO}

Hasta este momento se ha tratado de, en un breve rastreo, problematizar la manera en que se instalan ciertas verdades, principalmente la tecnología de gobierno (psyche) que se ha heredado y encarnado a partir de ciertos juegos de verdad en las subjetividades y, en lo particular, en una disciplina académico-pedagógica como la educación física. Tal es su relación con el cuerpo-movimiento, que

quien lea la alegoría de la caverna en la república de platón a la luz de la historia griega. Comprenderá en seguida que el periagôgê, el giro que Platón exige a la filosofía, equivale en realidad a un orden del mundo homérico. No es la vida tras la muerte, como en el hades homérico, sino la vida corriente en la tierra lo que se localiza en una "caverna", en un averno; el alma no es la sombra del cuerpo, sino que ésta es la sombra del alma, y el movimiento sin sentido, fantasmal, que atribuye homero a la existencia sin vida del alma en el hades tras la muerte, se atribuye a las acciones sin sentido de los hombres que no abandonan la caverna de la existencia humana para contemplar las ideas eternas, visibles en el firmamento (Arendt, 2005, pp. 317-318).

Lo anterior permite comprender cuál ha sido, a partir de la herencia griega, en el pensamiento occidental moderno, la forma de objetividad del mundo, y de realización del deseo para hallar una verdad, a partir de la cual, dándole sentido a las cosas, le dé sentido a la realidad y a la existencia humana que, per se, está condicionada por los objetos que produce, las relaciones posibles de establecer con estos y cómo puede acceder a ellos, pues de lo contrario generarían un caos, un no mundo (Arendt, 2005, pp. 17-20) y una 
no experiencia, además de impedir que el ser humano se entienda a sí mismo como un ser consciente de su cuerpo y su finitud, un ser que al contrario de la "contemplación teórica", necesita de otros para dar sentido a su existencia, ocuparse de sí mismo y devenir en otro, ser de otro modo, no echar raíz.

Justo ahí la sexualidad merece ser pensada como un horizonte de sentido de la existencia, pues "una y otra vez se ha subrayado que el sexo -la condición viril o femenina de la persona impregna y cualifica todas las actividades del ser humano" (Lain, citado por Suárez, 1995, p. 77), lo cual es heteronormativi$d a d^{6}$. Entonces es preciso repensar la sexualidad y no reducirla al cuerpo como soma, desde la genitalidad, sino a partir de la capacidad del cuerpo de dejarse afectar en relación con otros, allí existe la posibilidad expansiva de definirse a sí mismo en la narración con otro, en la donación de darse en la palabra y en cuerpo, luego abrirse a la del otro. Esto representa una posibilidad de resistencia dentro de la multiplicidad de relaciones que son posibles, al superar la siempre pretendida identidad fundamentalmente a la hora de referirse al dispositivo de la sexualidad.

A su vez, es innegable el aporte de la cultura griega respecto al ocuparse de sí y a la inquietud de sí, pues "la épiméleia es el principio filosófico predominante en el modo de pensamiento griego, helenístico y romano" (Foucault, 1994, pp. 33-34), horizonte ético ya tocado por el autor en La hermenéutica del sujeto (1994) y que aquí es tenido en cuenta en un sentido profundamente práxico para la educación física, siempre que sea posible para el sujeto de aprendizaje, hacer de sí mismo una estética de la existencia. Para ello es necesario repensar las prácticas de la educación física, teniendo en cuenta fundamentalmente el momento por el que pasa el país en materia de derechos humanos, sobre todo a la hora de referirse a la sexualidad y las formas posibles de ser cuerpo que permite el entramado de significaciones, sentidos y

6 Esta heteronormatividad enunciada por Butler, expresa una relación de saber-poder dentro del dispositivo de la sexualidad, el cual acaece sobre el cuerpo estableciendo una inteligibilidad sobre el mismo a partir de una relación causal entre sexo-género-deseo desde la cual los sexos opuestos se atraen. De ahí la necesidad de otorgarle una importancia a Herculine, un caso de hermafroditismo que al exceder el binarismo, es acaparado por el dispositivo de la sexualidad con la intención de otorgarle una identidad inteligible del "sexo verdadero" a partir de la normatividad del momento (Butler, 2007, p.82). afectos en medio de los juicios estéticos atroces en los que sucumbe la cultura colombiana.

A partir de ellos se ve el cuerpo del otro distinto, como el receptáculo de violencias simbólicas y físicas expresadas en la sangre y el silencio, en búsqueda, supuestamente, de una purificación cultural. Esto disminuye la capacidad de obrar de los cuerpos que se narran como distintos (Barrero, 2011, pp. 43-108), diversos y fuera de la heteronormatividad, o en casos en los que las mujeres quieren decidir sobre sus propios cuerpos, o la posibilidad de configurar una familia entre personas del mismo sexo y en cuyo caso precisamente, la educación física resulta ser funcional, esencialmente al privilegiar y reproducir valores acerca del cuerpo como masculino, joven, atlético, limpio, de tipo burgués y blanco (Pessolano, 2016).

Habría que decir, en procura de hacerle justicia a Spinoza (1980) y poniéndolo en el contexto colombiano en relación con lo que aquí se ha tratado de expresar, que esa necesaria comprensión del cuerpo hoy, que lo entiende dentro del entramado de relaciones en las cuales todos los cuerpos en su diversidad y pluralidad son indispensables en la "Red vital". Esta categoría es reclamada como derecho la Organización Nacional Indígena al Centro de Memoria Histórica (2019), quienes entienden el "cuerpo como comunidad" (Centro Nacional de Memoria Histórica, 2019, p. 199), y denuncian lo que históricamente han vivido en sus comunidades con la "mala muerte", 7 como ellos llaman, la cual representa una ruptura de esa red que los relaciona con la naturaleza y los saberes que ellos han tejido con la palabra, en la narración, pues son sujetos eminentemente orales.

Esto, por supuesto, representa un reto para la educación física y exige una sensibilidad especial de maestras y maestros para leer la realidad y abrirse a la realidad corpórea de sus estudiantes. Ello demanda claramente un esfuerzo intelectual para superar el paradigma cartesiano, desde el ya enunciado giro corporal $^{8}$ desarrollado por varios investigadores; aquí en

7 Según la Organización Nacional Indígena (oNIC), la "mala muerte" tiene que ver con la muerte violenta y desaparición en el conflicto, dentro de las dinámicas de despojo y explotación en los que están implicados los territorios y también se afecta la "red vital" de las comunidades originarias, la "mala muerte" quita el derecho a una "buena muerte", que es la muerte natural. (Centro Nacional de Memoria Histórica, 2019, pp. 165-202)

8 Para esta noción aludiré al concepto de Spinoza de que "nadie sabe lo que puede un cuerpo" y este es el punto de giro para 
Colombia, con exponentes como Margarita Benjumea (2009) quien en Elementos constitutivos de la motricidad como dimensión humana, resalta el valor de un sujeto en movimiento intencionado y consciente en-el-mundo recurriendo al paradigma fenomenológico, superando el paradigma mecanicista, en tanto el maestro eduque con fines de transformación, transformándose y leyendo la realidad desde la anécdota, la narrativa, que es territorio, cuerpo y comunidad, en un momento en el cual la educación necesita repensarse en el país.

Desde esta perspectiva, la educación física ha de ocuparse de las prácticas que tradicionalmente ha puesto a circular y de las experiencias que ha posibilitado para pensar, entonces, en sus dos corrientes o tendencias hegemónicas:

Deporte y condición física como régimen de pensamiento, las cuales han tenido funciones políticas en la administración de la vida y los cuerpos. Después de todo, el deporte escolar, emergente dentro de las escuelas gimnásticas inglesas, instituyó la formación moral, el control disciplinar y de la conducta (Mosquera et al., 2005, p. 29) y la condición física para la salud, en consonancia con el deporte, en la administración de vidas. Pero, desde discursos propiamente médicos, cumplen un ejercicio correctivo e higienista, en el que a partir de enunciaciones como el fitness y el wellness se pretende un equilibrio psicosomático que incluya lo mental, lo moral y lo físico (Mosquera et al., 2005, p. 7).

Estas dos tendencias o corrientes han tenido, por un lado, gran influencia en el currículo de la educación física circulando sus contenidos, pero, por el otro, han estado remotamente escindidas de una reflexión de su práctica y han resultado ser funcionales y vinculadas al modo de producción capitalista que, ideológicamente, puede ser considerada como un contenedor de valores y actitudes burguesas en las que caben la competitividad, el respeto por la propiedad privada y la autoridad, el patriotismo, la disciplina en el tra-

una filosofía del cuerpo. Además de Nietzsche y su exaltación del cuerpo, es en el siglo xx en el que se apunta hacia un giro corporal con autores como Maurice Merleau Ponty, quien enuncia al cuerpo como el "Ser" de la subjetividad, el "Ser" del pensamiento y con ello el modo en que accedemos al ser, luego nos revelamos a nosotros mismos como ser (Suárez y Verano, 2018). bajo y la masculinidad (Havergreaves, citado por Kirk, 2002, p. 147).

Sin embargo, lo profundamente importante aquí, en relación con el sujeto y con su cuerpo, son las tecnologías de gobierno ${ }^{9}$ que se instalan; en otras palabras "se nos enseña cómo pensar nuestros cuerpos y cómo experimentarlos" (Mclaren, 1993, p. 93), esto es, condicionar la experiencia corporal, las formas de encarnar el propio cuerpo, pero muy lejos de ello, "las subjetividades desbordan y exceden las racionalidades instrumentales" (Cachorro, 2009, p. 13).

¿Cuál es, entonces, la relación y posibilidad que existe, si es que existe, entre la sexualidad, la praxis de la educación física y la realidad colombiana? Tratando de tomar distancia de las cuestiones ya ampliamente relacionadas en lo referente a la sexualidad, lo que pretende este texto es encontrar en ella una manera de devenir permanentemente en otro. Esto es, darle un sentido ontológico a la sexualidad en cuanto experiencia que muere con nuestros cuerpos. Ello por supuesto, implica una posición ética frente a la vida, la conciencia de la finitud y fragilidad propia, luego la relación que merece ser establecida con otros cuerpos y con el mundo.

Hasta aquí se ha tratado de superar la idea dual de lo humano, el desprecio por el cuerpo y el sexo en cuanto asignación de un cuerpo a partir de categorías casi siempre emergentes del discurso médico y moral. Lo preocupante es que no se caiga en reduccionismos antropomórficos ${ }^{10}$ de la genitalidad, el género, la identidad sexual u otros discursos que pretendan instalarse como verdad, lo cual no ignora las luchas y los logros, fundamentalmente de las mujeres, los cuerpos más oprimidos, sobre todo el de la mujer indígena, negra y raizal, ni mucho menos se pretende construir desde un discurso traducido a partir de una "moral de hombres" (Foucault, 1984).

Es necesario, entonces, tomar una posición frente a la sexualidad, desentrañando ya no sus ejercicios de subjetivación, encausamiento y normalización, sino,

9 Como tecnología del yo, o de gobierno, se considerarán las operaciones que el sujeto hace por su cuenta o con ayuda de otros, sobre su cuerpo y sobre su alma (Foucault, citado por Pacheco, 2012)

$10 \mathrm{Al}$ referirse a lo antropomórfico, se hace alusión a lo que tiene que ver con la genitalidad y sus diversos usos en la explicación del cuerpo en términos reproductivos, patológicos y del concúbito. 
muy por el contrario, su posibilidad expansiva, ${ }^{11} \mathrm{de}$ resistencia y de agenciar experiencias estéticas en relación con otros sujetos. Se adoptará, pues, un neologismo desarrollado en un trabajo de Gabriel Suárez Medina (1995), quien de manera interesante desarrolla el concepto de sexualidad, "reemplazándolo" por sexuidad ${ }^{12}$ con la intención de descargarlo de todo reduccionismo llevado al plano de la genitalidad y de toda carga histórico-social; para en su lugar enunciarla en términos de Xavier Zubiri, como una nota de sustantividad del hombre, esto es, como una dimensión en la cual el ser humano cabe en su totalidad (Suárez, 1995).

El lugar de esto dentro de la educación física es, fundamentalmente, una relación ética consigo mismo que desborda los usos y discursos sobre el cuerpo, los cuales configuran la propia experiencia humana. Cerca está la sexuidad, como una narrativa que, en cuanto experiencia poética, sea sensible y por lo tanto estética. Esto permite superar los propios discursos y prácticas de la educación física y la estética atroz en la cual sucumbe la experiencia corporal del colombiano, para en su lugar posibilitar nuevos juicios estéticos en comunidad, que incluyan el mundo del otro distinto (Del Rosario y Gutiérrez, 2019).

Ese potencial de la sexuidad, según pretenden expresar estas líneas, radica en lo que Deleuze (2002) llamó el "cuerpo sin órganos", como ya lo ha tratado este texto. Es la superación de toda verdad de que el sujeto se piense y viva como sujeto inacabado, jamás definido por una doctrina teológica, filosófica ni de ninguna índole y por el contrario en permanente composición y recomposición; un sujeto cuya vida solo pueda ser enunciada en la muerte. Esta posibilidad vital de enunciar la vida en cuanto tal, exaltando al cuerpo como abierto y en advenir, esto es, abierto a la experiencia, en condición de nómada, un sujeto que no echa raíz y que desterritorializa y reterrito-

11 Se define, en términos de Deleuze (2002), como líneas de fuga que sacan al sujeto fuera de sí y sea posible hacerse a un cuerpo sin órganos. Para este artículo, lo expansivo se verá como narrativa, dimensión poética desde la cual es posible crear una estética de la existencia, un cuerpo como territorio y obra de arte.

12 Partiendo de la no reducción del ser humano a su sexo, este concepto alude a la totalidad del sujeto, a la inteligencia sentiente con la que puede darse cuenta de su unidad y de su realidad. rializa su ser con una actitud expansiva y capaz de entregarse a la sorpresa y a la perplejidad de la vida.

Esto podría claramente propiciar otras formas de saber sobre el cuerpo que, superando el dualismo en y a partir de una experiencia sensible, permita al sujeto darse cuenta de que no tiene un cuerpo, como se tiene cualquier objeto del que es posible deshacerse y rechazar como si el cuerpo fuera una exterioridad, si no que él es su cuerpo y en su sexuidad, puede dar un valor distinto y ejercer un juicio estético diferente de las cosas que permita contemplar nuevos horizontes de sentido, además de abrirse a la relación con otros sujetos, pues de esa forma es que puede definirse a sí mismo, debido a que no es que el cuerpo exista y además y por fuera de él hayan cosas y sujetos, sino que el sujeto, el cuerpo, consiste en estar abierto a las mismas. La sexuidad es pues una puerta de salida y entrada en la realidad corpórea del sujeto, con el mundo de los demás cuerpos, es una expresión manifiesta de la inteligencia sentiente con la que el ser humano dando cuenta de su finitud, exalta su voluntad de verdad, de no echar raíz y apreciar cada encuentro con la disposición, intencionalidad y conciencia que requiere (Suarez, 1995).

¿Cuán lejos se puede estar, hasta este momento, de la motricidad y de la experiencia corporal? ¿Qué puede insinuarnos ahora la sugestiva pregunta de Díaz (2007), respecto a qué nos insinúa la "experiencia corporal"? Es muy posible que lo planteado hasta aquí sea una primera "pincelada" para que el lector pueda continuar un ejercicio propio. Sin embargo, es claro que estas son herramientas discursivas y prácticas, las cuales, permiten superar la reducción usual, que hace la educación física de la experiencia humana.

Arendt (2005), mujer que padeció el nazismo, se refiere a este tipo de experiencia al aludir al trabajo y consumo, como la manera de hacer del ser humano un preso de sí mismo. Allí, la relación entre vida y metabolismo gastado rompe toda relación con el otro y la idea de comunidad (Del Rosario y Gutiérrez, 2019). Por el contrario, la posibilidad de hacer del cuerpo y la vida una obra de arte implica una narración que disienta y se resista a los totalitarismos. En un país como Colombia, acostumbrado a la muerte, se crea una base antropológica en la que el placer y la muerte del otro se configuran como formas de 
vivir, mediante arquetipos avalados y consensuados gracias a complejos ejercicios de adoctrinamiento y enraizamiento ideológico basados en el terror y el pánico, con los cuales, perversamente, se van esculpiendo en el inconsciente colectivo el sectarismo, el dogmatismo y el autoritarismo; allí, consustancialmente el placer de conocer y sentir tanto el terror como la compasión representa una de las dimensiones de lo que aquí se ha enunciado como "estética de lo atroz" (Barrero, 2011).

En lugar de ello, y a propósito del "cuerpo sin órganos”, Del Rosario y Gutiérrez (2019) ponen en diálogo a Arendt y Deleuze, en el sentido de que toda narración es posibilidad de enunciación vital y desestabilización de los valores que se instalan como verdad. Así, la narración como expresión artística, para Arendt, es una forma de supervivencia para conciliar con la tragedia y poder resistirse a la penuria de los campos de concentración. Es de esa manera que los sentidos expresados toman forma en la comunidad, pues ella es testigo de la vida narrada, luego, ella es capaz de asirla, transformarla, recrearla y resignificarla para que aparezca un nuevo horizonte de sentido en el cual pueda estar incluida la pluralidad de voces no escuchadas (Del Rosario y Gutiérrez, 2019).

Entender la importancia de la experiencia corporal radica en darle un sentido estético y apelar a la sexuidad como un umbral, como un finísimo límite de encuentro con el otro, un influjo desde el cual es posible relacionarse con el mundo que ha de ser una aventura con horizonte, pero sin rumbo. Un encuentro con otro cuerpo, desequilibra la experiencia propia, saca al sujeto fuera de sí y lo arroja en la multiplicidad y en la totalidad del otro, en sus máscaras y en su misterio, un juego erótico en el cual no hay productividad alguna, pero del que es posible ir siendo y rehaciéndose. Tal es la importancia de la educación en lo general y la educación física en lo particular (puede ser: se tomen) tomen en serio la sensibilidad en un sentido profundamente práxico.

Definitivamente es la reflexión pedagógica, ${ }^{13}$ en cuanto praxis, el punto de inflexión en la superación de las relaciones humanas alienantes que constituyen

13 Cuando me refiero a esta reflexión pedagógica desde la práctica vuelvo a la frase de Foucault en la que "el maestro como sujeto del saber, llamado pedagogía, se relaciona con el conocimiento a través de la práctica pedagógica" (citado en Zuluaga et al., 2005, p. 22). al otro como objeto, objeto del que es posible recibir un beneficio y que, en todo caso, implica el uso de otro cuerpo como mera mediación autoerótica (Dussel, 2007). Esa reflexión debe pasar por el propio cuerpo y subvertir la idea de psyche para devenir en ese cuerpo sin órganos que es posible en la donación, en la experiencia expansiva y erótica de la no ganancia ni el beneficio, pero sí de la exaltación de la vida, pues, en palabras de Arendt (2005), "la vitalidad y viveza solo pueden conservarse en la medida que el hombre está dispuesto a tomar sobre sí la carga, fatiga y molesta de la vida" (p. 129).

Esa experiencia erótica solo es posible en cuanto juego, esta lleva al ser humano a perderse en sí mismo y con plena conciencia de ello, lo cual no es otra cosa que transgresión de toda religiosidad, fundamentalmente de la cristiana, que se presenta como antítesis del erotismo y posee además la capacidad de ubicarse por encima y negar, incluso, cualquier otra religión (Bataille, 2007). Es este el crisol para la muerte de dios, que tanto para Nietzsche (2010) como para Deleuze (2002) en su comprensión del cuerpo sin órganos, es la posibilidad de una ethopoiética vital, que se resista a los ejercicios de administración y gobierno de la vida, propios de una sociedad de control.

¿Cuál podría ser, hasta aquí, la diferencia y el valor entre despreciar la vida y reafirmarla? ¿Cuáles son los sentidos que nos sugiere la práctica pedagógica desde la educación física? Esta actitud frente a la vida, asumiendo la sexuidad como ethopoiética, como actitud ética y estética frente a la vida, no es ingenua ni banal. Por el contrario, implica la consciencia ${ }^{14}$ de huida de sí mismo, de la propia alma (psyche), de aquello que me configura como acabado y como sujeto de deseo. Pues es el alma la que atrapa al cuerpo, porque alma poseen las empresas (Deleuze, 1991) y estas últimas son productoras de deseo, el cual toma distintas formas en las subjetividades. Desde el perverso discurso de la vocación, por ejemplo, el sujeto se vuelve empresario y esclavo de sí mismo, se explota a sí mismo o, como bien lo

14 Cuando se habla de consciencia, es preciso regresar a Hegel en su dialéctica, cuando habla del paso de un ser en sí a un ser para sí, que, en este caso, un ser que huyendo de sí mismo, esto es, de toda verdad, de toda trascendencia, regresa a la inmanencia de su cuerpo y de su vida para abrirse a la experiencia del otro. 
expresa Arendt (2005): "La vida del esclavo atestigua que la vida es esclavitud" (p. 130). Esta afirmación atestigua la condición y experiencia humana. Del Rosario y Gutiérrez (2019) advierten, en términos de Arendt, cómo trabajo y consumo hacen del ser humano un preso de sí mismo, estableciendo una perversa relación entre vida y metabolismo gastado, algo que rompe toda relación con el otro y la idea de comunidad.

Es tal el papel del capitalismo en su fase neoliberal, que configura afectos y pasiones que no son nuestras, o como lo afirmó Deleuze (1991), esos afectos y esas pasiones perpetúan la estructura del capitalismo, hacen del sujeto un empresario de sí mismo. Por ello, escapar de sí mismo, escapar del alma es, pues, una forma de estar abierto al mundo, a la experiencia corporal; un cuerpo sin órganos que vive su sexuidad en relación con otros seres humanos. Distinto es educar al otro en preservar la vida exaltando al cuerpo y su sabiduría ${ }^{15}$ que negar la diversidad del pensar, sentir, vivir el cuerpo, para abrirse a la experiencia del otro.

\section{CONCLUSIONES}

¿Qué es la sexualidad si no un discurso y un dispositivo que, reduciendo el cuerpo a la genitalidad, a un órgano, desprecia precisamente al órgano y con ello al ser humano? ¿Acaso no es un discurso y dispositivo con el cual las relaciones ejercidas entre tal o cual, con otros seres humanos, con otros cuerpos, se remite a su función reproductiva, lo que implica una clasificación binaria y una mirada eminentemente económica? Por eso es preciso seguir prestando atención, a ese órgano, al discurso y al dispositivo para que, aprehendiéndolos y reconstruyéndolos en el complejo y acuoso campo del lenguaje, se diluyan $\mathrm{y}$ fundan en el cuerpo como un crisol que devenga en otras experiencias.

¿Por qué ha de ser considerada la sexuidad cómo praxis y cómo poiesis? Eludiendo toda futilidad, reflexionar en torno a esta dimensión humana, lleva a pensarla desde estos dos pilares propios de toda condición humana. Primero, porque en la sexuidad es posible pensar en transformaciones a partir de la

15 La idea de sabiduría del cuerpo es una exaltación del mismo y una posición muy nietzscheana, en la cual, como enunció este autor en el Zaratustra, el alma es algo que está en cualquier lugar del cuerpo. base, aquí, desde la experiencia corporal; es decir, de lo particular a lo general, lo cual es praxis. Segundo, porque puede ser considerada poiesis en cuanto parte de un sujeto que sale de sí mismo, para sí mismo, lo cual le permite contemplar y hacer una ethopoietica de su existencia y poder superar los microfascismos que pasan imperceptiblemente frente a nuestros ojos, sobre todo al hablar de la sexualidad.

\section{REFERENCIAS}

Aguilar, D., Caruso, M., Echeverri, J., Martínez, A., Narodowski, M., Noguera, C., Quiceno, H., Rifà, M., Runge, A., Sáenz, J., Saldarriaga, O., Schérer, R., Veiga-Neto, A., Vitarelli, M. y Zuluaga, O. (2005). Foucault, la pedagogía y la educación. Bogotá: Cooperativa Editorial Magisterio.

Arendt, H. (2005). La condición humana. Buenos Aires: Paidós.

Barrero, E. (2011). Estética de lo atroz. Psicohistoria de la violencia política en Colombia. Bogotá: Cátedra Libre.

Bataille, G. (2007). El erotismo. http://www.pensamientopenal.com.ar/system/files/2014/12/doctrina31464. pdf

Benjumea, M. (2009). Elementos constitutivos de la motricidad como dimensión humana. [Tesis de grado, Universidad de Antioquia].

Cachorro, G. (2009). Deporte, prácticas corporales y subjetividad. Artefacto, pensamientos sobre la técnica. http:// www.kimerius.es/app/download/5788938993/ Deporte,+pr\%C3\%A1cticas+corporales+y+subjetividad.pdf

Del Rosario, M., y Gutiérrez, A. (2019). Narración, resistencia y sentido en Hannah Arendt y Gilles Deleuze. Revista Valenciano, (23), 174-189.

Deleuze, G. (1991). Posdata sobre las sociedades de control. http://www.fundacion.uocra.org/documentos/recursos/articulos/Posdata-sobre-las-sociedades-de-control.pdf

Deleuze, G. (2002). Mil mesetas, capitalismo y esquizofrenia. Valencia: Pre-Textos.

Díaz, A. (2007). ¿Qué nos insinúa la "experiencia corporal"? Lúdica Pedagógica, 2(12). https://doi.org/10.17227/ ludica.num12-7673

Dussel, E. (2007). Para una erótica latinoamericana. Caracas: El Perro y La Rana.

Foucault, M (1977). Historia de la sexualidad (vol. I). Madrid: Siglo XXI. 
Foucault, M. (1979). La arqueología del saber. México: Siglo XXI.

Foucault, M. (1984). Historia de la sexualidad (vol. II). Buenos Aires: Siglo XXI.

Foucault, M. (1994). Hermenéutica del sujeto. Madrid: La Piqueta.

Havelock, E. (1994). Prefacio a Platón. Madrid: Visor.

Kirk, D. (2002). Diseño del currículum: exposición y crítica del modelo por objetivos. En Educación física y currículum (pp. 116-136). Valencia: Universitat de València.

Mclaren, P. (1993). Formación escolar del cuerpo posmoderno: pedagogía crítica y política de encarnación. En Pedagogía crítica, resistencia cultural y la producción del deseo (pp. 79-125). Argentina: Rei Argentina-Aique.

Mosquera, L., y otros. (2005). Relación teoría-práctica en la educación física. Bogotá: Universidad Pedagógica Nacional.
Nietzsche, F. (2001). El anticristo. Madrid, España: Biblioteca Edaf.

Nietzsche, F. (2010). Así hablaba Zaratustra. México: Época.

Pacheco, C. (2012). La biopolítica en la actividad física, la calidad de vida y el cuidado de sí, discursos que legitiman la administración de la vida. Bogotá: Autores Editores S.A.S.

Sánchez, A. (2003). Filosofía de la praxis. Buenos Aires: Siglo XXI.

Suárez, G. (1995). La corporeidad sexuada: umbral de encuentro con el otro. Cuadernos de Filosofía Latinoamericana, 62, 62-91.

Suárez, J., y Verano, R. (2018). Pensar el cuerpo. Barranquilla: Universidad del Norte. 